\title{
MAPA DE CLIENTE-SOLUÇÃO: UMA FERRAMENTA DE APOIO À SERVITIZAÇÃO NO CONTEXTO DE UMA INCUBADORA CORPORATIVA DO SETOR DE ÓLEO E GÁS
}

Wesley Souza Junior (wesleycanedo@gmail.com) - Escola de Engenharia / Universidade Federal de Minas Gerais

Matheus Luiz Pontelo de Souza (mslzposa@gmail.com) - Pontifícia Universidade Católica de Minas Gerais - PUC Minas

Leonel Del Rey de Melo Filho (leoneldr@pucminas.br) - Pontifícia Universidade Católica de Minas Gerais - PUC Minas

Raoni Bagno (rbbagno@gmail.com) - Escola de Engenharia / Universidade Federal de Minas Gerais

Cleudir José de Castro Junior (cleudir.junior@gmail.com) - Pontifícia Universidade Católica de Minas Gerais - PUC Minas

\section{RESUMO}

Um número crescente de empresas tem adotado abordagens como a servitização e o desenvolvimento interno de startups, usualmente realizado por meio de incubadoras corporativas, na busca por maior competitividade. Embora tenham propósito similar, o desenvolvimento de soluções inovadoras, a literatura carece de ferramentas que colaborem para a adoção dessas duas estratégias simultaneamente. Por meio de um projeto que articula princípios da pesquisa-ação com grounded theory aplicado em uma indústria do setor de óleo de gás, o estudo propõe uma ferramenta que combina conceitos importantes da servitização (e.g. entendimento de demandas mais amplas de clientes nos quais a base de produtos da empresa está instalada), bem como conceitos do desenvolvimento de startups (e.g. entendimento da jornada do cliente, seus ganhos e dores associadas) na condução do desenvolvimento de soluções inovadoras com melhores resultados para a empresa. As principais implicações dessa ferramenta são a facilitação da tomada de decisão em nível 
estratégico, tático e operacional, e uma melhor condução da rotina de trabalho de uma incubadora corporativa.

Palavras-chave: Ferramentas de inovação; Startup; Incubadora corporativa; Servitização; Indústria do setor de óleo e gás. 


\section{INTRODUÇÃO}

A permanência de empresas manufatureiras apenas com atividades produtivas dentro da cadeia de valor tornou-se menos atrativa, na medida em que a demanda por produtos tem-se estagnado (WISE; BAUMGARTNER, 1999) e os produtos se tornam "comoditizados" com grande facilidade (KASTALLI; VAN LOOY, 2013). A fim de responder aos novos desafios, algumas abordagens de atuação têm sido implementadas por indústrias e retratadas pela literatura. Uma delas tem sido a agregação de valor a negócios por meio da incorporação de serviços (VANDERMERWE; RADA, 1988), buscando alcançar potenciais ganhos econômicos e competitivos para o negócio (OLIVA; KALLENBERG, 2003). Esta estratégia é denominada Servitização (VANDERMERWE; RADA, 1988), enquanto a referência a ofertas de produtos e serviços integrados, dentre várias nomenclaturas utilizadas, pode ser referenciada como Sistema Produto-Serviço (Product-Service System - PSS) (PARK; GEUM; LEE, 2012).

Um movimento que ocorre em paralelo ao contexto acima descrito é a busca de engajamento de empresas estabelecidas com startups. Tais empresas, de modo geral, têm buscado maneiras de se tornarem mais inovadoras e empreendedoras tal como as startups (WEIBLEN; CHESBROUGH, 2015) e, nesse caso, a replicarem internamente as metodologias aplicadas por elas. Exemplos desses engajamentos são incubadoras internas, venture-capital corporativo, alianças estratégicas e joint ventures (KOHLER, 2016; WEIBLEN; CHESBROUGH, 2015), sendo a incubação interna apontada como uma das alternativas mais consolidadas neste campo (WEIBLEN; CHESBROUGH, (2015).

Embora sejam temáticas consideradas distintas na literatura, as estratégias de servitização e de desenvolvimento de startups apresentam propósitos congruentes: o desenvolvimento de soluções inovadoras. Enquanto na literatura de incubadoras corporativas a nova solução pode (i) se transformar numa startup e, assim, conquistar novos mercados independentemente (spinoff), ou (ii) ser reintegrada como uma divisão separada (WEIBLEN; CHESBROUGH, 2015), na literatura de servitização a segunda opção é a mais comum (e.g. KASTALLI; VAN LOOY, 2013; WISE; BAUMGARTNER, 1999). O desenvolvimento de startups cujas soluções estejam relacionadas ao corebusiness da empresa mãe pode ser uma importante alternativa para uma indústria cuja inovação no produto exija altos investimentos pois, segundo Wise e Baumgartner (1999), mercados a jusante na cadeia produtiva tendem a ter margens mais elevadas e a exigirem menos ativos do que a fabricação do produto. Sendo assim, o desenvolvimento de soluções inovadoras que envolvam serviços atrelados aos produtos pode ser um importante ponto de 
partida. Além disso, este caminho pode, potencialmente, minimizar os riscos de investimento por se tratar de um campo de atuação relativamente conhecido pela empresa mãe. A literatura, contudo, é pobre em referências que tratem, conjuntamente, a servitização e o desenvolvimento de startups de origem corporativa num mesmo contexto, sobretudo a respeito de ferramentas que possam integrar a gestão das duas perspectivas. Ferramentas de apoio em cada uma das vertentes são limitadas quanto a uma visão holística e integrada para tomada de decisão nos níveis estratégico, tático e operacional durante o desenvolvimento de soluções inovadoras. A partir dessa lacuna, uma indagação é levantada: como integrar/combinar a abordagem de servitização e o desenvolvimento interno de startups para geração de novas soluções inovadores em uma empresa estabelecida? Esta é a lacuna que este trabalho visa explorar.

\section{REVISÃO TEÓRICA}

\subsection{Servitização}

A Servitização (Servitization) é definida como o processo de mudança da estratégia de negócio a partir da qual as indústrias adotam uma orientação para serviços e/ou desenvolvem mais e melhores serviços com o intuito de: satisfazer as necessidades dos clientes, obter vantagens competitivas e melhorar seu desempenho (REN; GREGORY, 2007). De forma complementar, Kastalli e Looy (2013) afirmam que a Servitização pode ser vista como o desenvolvimento da capacidade de inovação de uma organização cuja estratégia esteja limitada à oferta de produtos para passar a oferecer Sistemas Produto-Serviço (Product-Service System - PSS), isto é, soluções que envolvam a entrega de produtos e serviços combinados.

A transição de produtos para soluções produto-serviço é, contudo, geralmente difícil para uma empresa que construiu sua estratégia em torno de negócios envolvendo novos produtos (BRAX, 2005) sendo, então, considerada um grande desafio gerencial (OLIVA; KALLENBERG, 2003). A falta de teoria e melhores práticas têm levado empresas de manufaturas a tentarem por elas mesmas moverem-se a jusante na cadeia de valor, isto é, atuar na direção da prestação de serviços necessários para operar e manter seus produtos fabricados e em uso pelo cliente (base instalada) (WISE; BAUMGARTNER, 1999), com um variado grau de sucesso (KARLSSON, 2007). Baines et al. (2009) cobra papel proativo de acadêmicos para se desenvolver métodos e técnicas que possam ser utilizadas por praticantes como auxílio ao projeto de serviços, bem como ferramentas que apoiem o desenho de estratégias que propiciem a oferta de PSS. Numa 
pesquisa bibliográfica recente, Song e Sakao (2017) destacam que embora haja alguns esforços de pesquisa na definição, benefícios e classificação do PSS, a literatura ainda é vaga em suportes metodológicos que cubram todo o processo de desenvolvimento e implementação do PSS. Algumas ferramentas como Casa da Qualidade, TRIZ e Diagrama de serviços são sumarizadas pelo estudo, embora sejam limitadas quanto a uma visão holística e integrada para tomada de decisão nos níveis estratégico, tático e operacional.

\subsection{Desenvolvimento interno de startups: incubadoras corporativas}

O objetivo de empresas estabelecidas em colaborar com startups tem sido transformá-las em motores de inovação corporativa, iniciativa esta que tem aumentado nos últimos anos. Essa aproximação pode se dar por meios diversos como incubadoras internas, venture-capital corporativo, alianças estratégicas, joint ventures (KOHLER, 2016; WEIBLEN; CHESBROUGH, 2015), engajamentos em hackatons corporativos e incubadoras de negócios (KOHLER, 2016). Como exemplo, para se beneficiar das ideias "desajustadas" que surgem dentro da empresa e não se encaixam no atual corebusiness ou no modelo de negócios, as incubadoras corporativas emergiram como um meio de trazê-las para o mercado como novas empresas. Esse ambiente interno focado em ideias também internas fornece ao empreendimento incipiente: financiamento, co-localização, expertise e rede de contatos. A intenção é fornecer à equipe um ambiente semelhante ao de uma startup a partir do qual a inovação radical possa crescer melhor do que se estivesse na organização parental, via de regra, lenta e burocrática. Exemplo de empresas que implementaram com sucesso uma incubadora corporativa são Xerox, IBM e BOSCH (WEIBLEN; CHESBROUGH, 2015).

Algumas ferramentas de gestão para estes ambientes de inovação se destacam, como Roadmapping, Business Model Generation (BMG), Value Proposition Design (VPD) e Jornada do Cliente se destacam nesse ambiente.

O Roadmapping pode ser definido como um framework visual estruturado que é usado para suportar a definição de processos de inovação e estratégia (PHAAL; FARRUKH; PROBERT, 2010). O método possui dois níveis principais de atuação: o primeiro voltado à estratégia de inovação (S-Plan) (PHAAL; FARRUKH; PROBERT, 2007), e o segundo voltado ao planejamento de produtos/tecnologias (T-Plan) (PHAAL; FARRUKH; PROBERT, 2001). A Figura 1 - apresenta um roadmap genérico. 


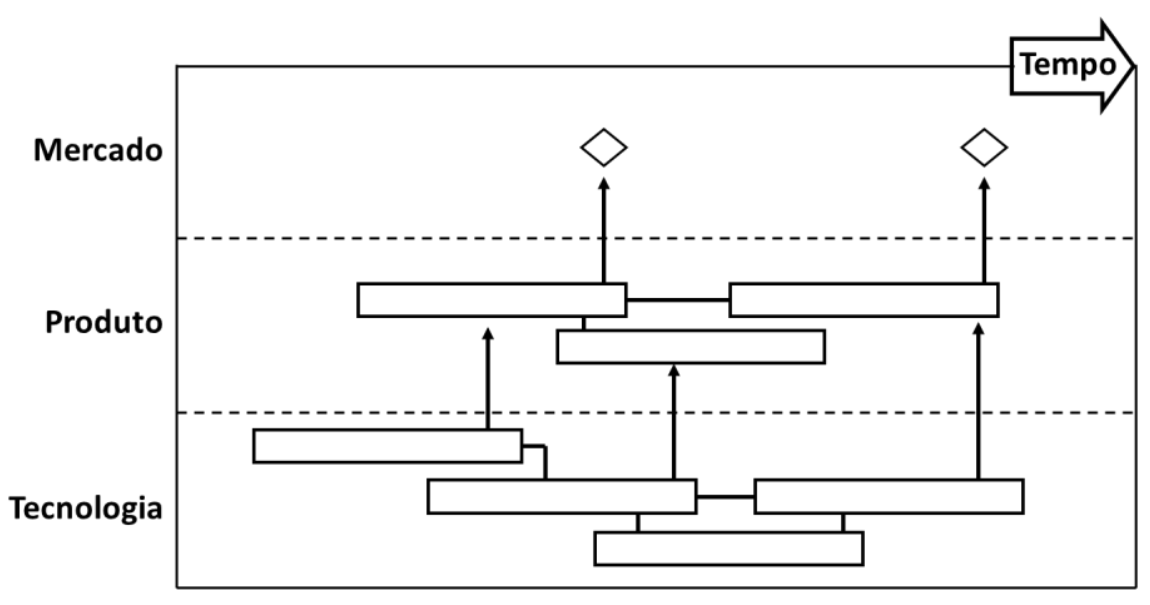

FIGURA 1 - Roadmap genérico

Fonte: Adaptado de Phaal et al. (2004)

O Value Proposition Design (VPD), um dos campos do Business Model Generation (BMG), é caracterizado como um enfoque no pacote de produtos e serviços que soluciona problemas e/ou satisfaz necessidades de segmentos de clientes. Seu objetivo é conduzir à identificação de propostas de valor que os consumidores desejem (OSTERWALDER et al., 2014). Para melhor entendimento do perfil do cliente, os mesmos autores propõem a avaliação de três dimensões: (i) atividades do cliente, que representa o que eles tentam realizar em seu trabalho ou em suas vidas; (ii) suas dores, que representam as dificuldades que os clientes possam vivenciar para realizar suas atividades; e (iii) seus ganhos objetivados, que expressam aqueles elementos que fariam as atividades dos clientes mais fáceis, seus objetivos e sua percepção de sucesso. Para profundo entendimento do perfil do cliente e suas dimensões, os autores recomendam a técnica denominada Jornada do Cliente, na qual a equipe de desenvolvimento busca experimentar, se possível mediante contato real com a realidade, toda a experiência temporal do cliente ao lidar com um problema/situação específico.

\section{METODOLOGIA}

Esta pesquisa combina Pesquisa-Ação (PA) e Grounded Theory (GT): a primeira foi usada como estratégia de condução geral e relação com o fenômeno investigado e a segunda como base para o processo de entendimento da realidade e identificação do problema.

A indústria onde se realizou a pesquisa é do setor de óleo e gás e está localizada em Minas Gerais. Dificuldades como a comoditização de produtos, a abertura do mercado brasileiro para novos players de mercado e o acirramento da competitividade motivaram essa empresa a 
investir em novas oportunidades de atuação. Para tanto, foi dado o desafio de desenvolver startups a uma equipe multidisciplinar composta por membros de diferentes departamentos. Dificuldades dessa equipe em lograr êxito motivaram a contratação de uma consultoria para apoio na condução das atividades.

A abordagem de atuação dos pesquisadores teve início com o questionamento orientativo da GT: what's going on here? (GLASER, 1992 apud TAROZZI, 2011). Por que resultados efetivos e ações eficientes durante o desenvolvimento de soluções não aconteciam nesse novo ambiente de trabalho criado? Embora diversas categorias de problemas tenham emergido da prática como resposta a essa questão, o recorte aqui analisado diz respeito aos desafios relacionados à tomada de decisões estratégicas/táticas/operacionais no nível de análise do programa e projeto dessa incubadora.

O trabalho envolveu a participação direta (i.e. discussão sobre como se equacionar uma solução para a problemática) de cinco colaboradores de diferentes níveis hierárquicos envolvidos na iniciativa da empresa, e de pelo menos 25 colaboradores de forma indireta (i.e. interação com as versões criadas e feedback). O desenvolvimento completo da ferramenta aconteceu num período de 8 meses, entre 2017 e 2018. As etapas de desenvolvimento envolveram, sequencialmente: entendimento do contexto de trabalho e seus desafios; levantamento e priorização dos entraves da rotina; levantamento e priorização de ideias de solução que resolvessem os problemas priorizados; esboço de estruturas que melhor gerenciassem as informações sensíveis; coleta de informações para povoamento da estrutura definida; validação cruzada das informações levantadas com diferentes colaboradores da empresa; apresentação da ferramenta criada para as equipes de trabalho; aplicação prática e interação com a ferramenta pelas equipes de desenvolvimento; coleta de feedback dos envolvidos via conversas individuais, via grupos focais e via observação do uso da ferramenta; atualização conjunta da ferramenta por pesquisadores e colaboradores; atualização isolada das ferramentas por colaboradores; observação e avaliação da nova rotina de trabalho e seus impactos na problemática inicialmente identificada. 


\section{RESULTADOS E DISCUSSÃO}

\subsection{A situação-problema}

Ao iniciar a participação na rotina de trabalho da equipe de desenvolvimento, os pesquisadores foram inseridos em reuniões que aconteciam quinzenalmente com os times de projetos. Em síntese, dois níveis de entraves foram observados durante a rotina: nível programa, o que envolvia decisões estratégicas de gestão da incubadora corporativa; e nível projeto, que envolvia decisões no âmbito tático/operacional de cada projeto individualmente. No primeiro nível, as seguintes dificuldades foram elencadas: (a) dificuldade de tomada de decisões em função do grande volume de informações oriundas dos diversos projetos (i.e. priorização de ações, mapeamento das intercessões de desenvolvimento entre projetos); (b) dificuldade em visualizar um panorama geral de atuação da incubadora; (c) perda de insights de ideias que emergiam no decorrer das reuniões, mas que se perdiam e não eram registradas. No segundo nível, as seguintes dificuldades foram observadas: (d) dificuldade de um entendimento holístico dentre os participantes sobre para qual cliente, e seu contexto de trabalho, eram direcionadas as funções técnicas em desenvolvimento; (e) dificuldade de priorização e sequenciamento no tempo das funções a serem desenvolvidas; (f) dificuldade em integrar as informações de todos os participantes para tomada de decisão, pois um certo vai e vem de participantes acontecia constantemente durante as reuniões, fisicamente ou virtualmente. Embora houvesse a intenção de presença de todos os colaboradores participantes, os esforços destes eram divididos entre as atividades da incubadora e as atividades de rotina de seus departamentos de origem).

\subsection{Métodos configurados: uma nova ferramenta de gestão}

Para dirimir os problemas emergidos, uma configuração de métodos foi proposta, construída em conjunto e implementada com a equipe interna da indústria. A solução criada envolve elementos das seguintes ferramentas: (i) mapas de Cadeia de Valor; (ii) Canvas da proposta de valor; (iii) Roadmapping; (iv) Servitização. O equacionamento dos problemas levou à construção de um mapa de gestão da atuação da indústria. Sua estrutura é apresentada na Figura $2-$. 


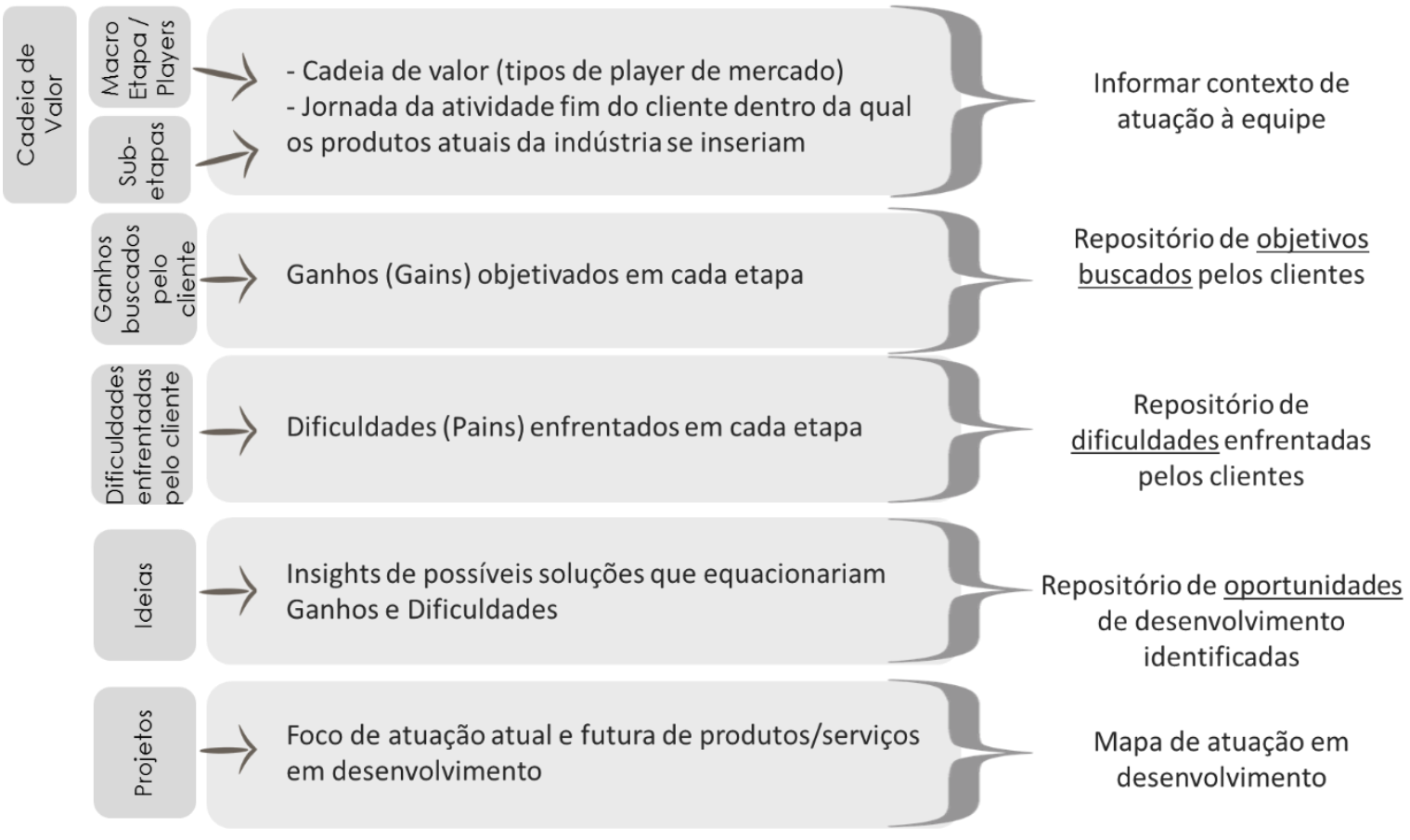

FIGURA 2 - Estrutura conceitual do mapa

Conforme apresentado na Figura 2 -, o mapa criado possui cinco camadas: (i) Cadeia de valor, subdividido em Macroetapas/Players e Subetapas; (ii) Ganhos buscados pelo cliente; (iii) Dificuldades enfrentadas pelo cliente; (iv) Ideias; (v) Projetos.

A primeira camada "Cadeia de valor", inspirado no VPD e no conceito de Cadeia de Valor, foi criado com o intuito de promover uma visão holística para toda a equipe sobre a jornada do cliente na cadeia dentro da qual a indústria tinha alguma intercessão, seja a montante ou a jusante. Nesse caso, decidiu-se subdividir esta camada em outros dois: Macroetapas e Subetapas. Uma vez que a jornada de trabalho não envolvia sempre o mesmo cliente, foram instituídas macro etapas com os nomes de categoria de clientes que atuavam nesse elo (e.g. Operadores, Governo). A segunda camada, Subetapa, instituiu-se um detalhamento maior de cada uma dessas macroetapas, representando atividades de forma sequencial que tangibilizassem a jornada da atividade fim do cliente dentro da qual os produtos atuais da indústria se inseriam.

Na camada "Ganhos buscados pelo cliente" (Ganhos), inspirado na ferramenta Canvas da proposta de valor, mapeou-se quais os principais objetivos que o cliente busca em cada uma das Subetapas representadas. Nesse caso, seu intuito era de prover consciência à equipe sobre os objetivos que as funções sendo desenvolvidas deveriam alcançar. 
$\mathrm{Na}$ camada "Dificuldade enfrentadas pelo cliente" (Dificuldades), também inspirado na ferramenta Canvas da proposta de valor, mapeou-se as principais dificuldades vividas pelo cliente durante a realização das Subetapas.

A camada de ideias (Ideias) tinha como objetivo funcionar como um repositório das ideias de soluções que pudessem prover os ganhos buscados pelos clientes nas Subetapas, ao mesmo tempo que solucionava em parte ou integralmente os problemas identificados na intercessão com a camada de Problemas.

A camada de projetos identificava quais das Subetapas de toda a cadeia mapeada que as soluções em desenvolvimento estavam procurando resolver. Esta camada se inspirou no campo da Servitização, no qual indústrias fabricantes de bens buscam uma atuação a jusante na cadeia de valor (WISE; BAUMGARTNER, 1999). Nesse caso, uma estratégia inicial seria a atuação sobre a própria base instalada de seus produtos. Aqui, porém, o conceito foi expandido para além da base instalada: houve o mapeamento adicional dos elos da cadeia que originavam a demanda de seus produtos (a montante).

A partir da estrutura apresentada na Figura 2 -, construiu-se uma matriz a partir da intercessão das Subetapas apontadas na camada de Cadeia de Valor (eixo x), com cada uma das outras camadas descritas anteriormente (eixo y). Nesse caso, a lógica do Roadmap foi utilizada: eixo y com camadas estratégicas e eixo x com uma visão temporal, aqui representadas pelo sequenciamento temporal de atividades. O resultado é o Mapa de Cliente-Solução (MCS) apresentado na Figura 3 -. 


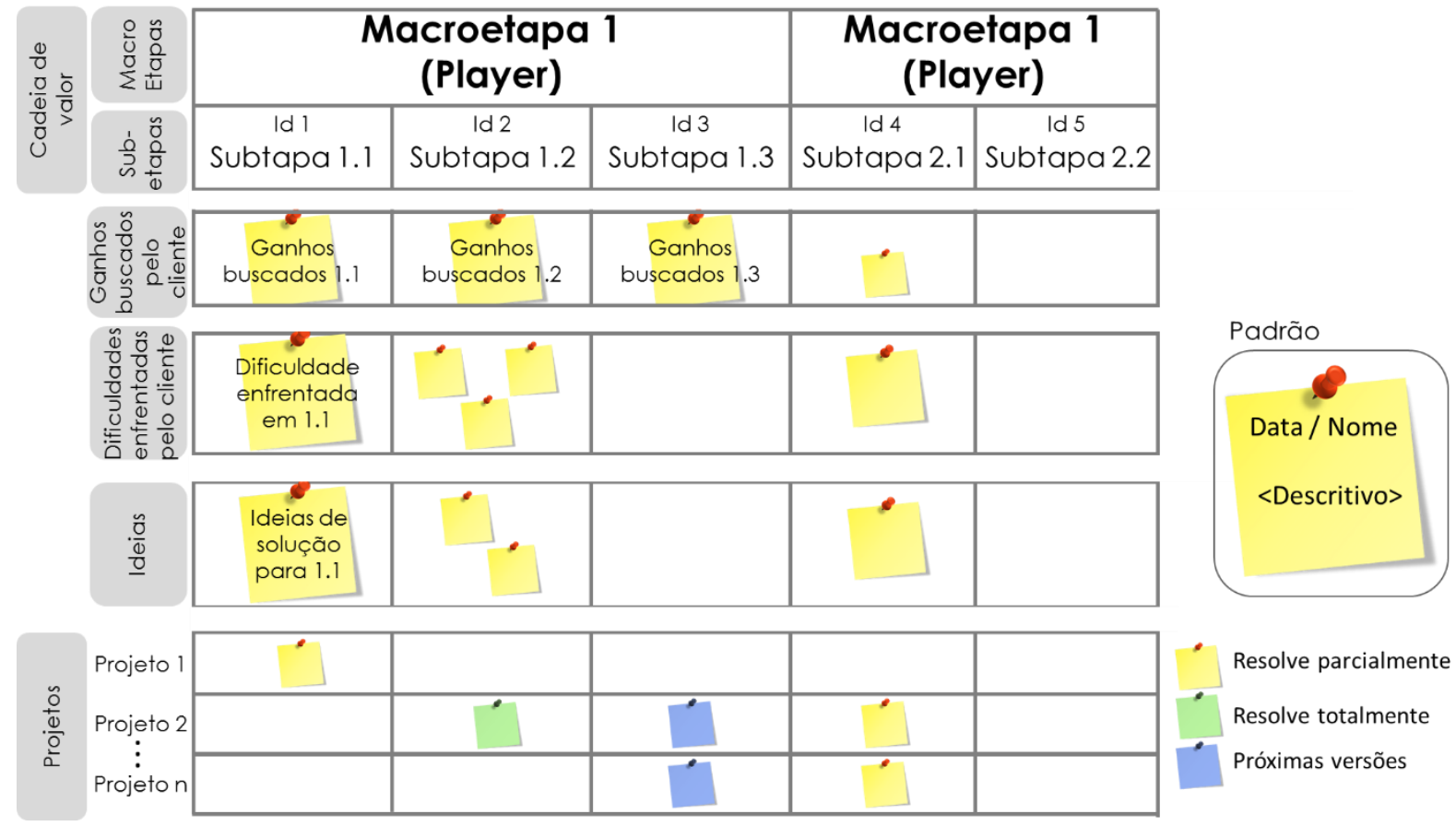

FIGURA 3 - Mapa de Cliente-Solução (MCS)

Na Figura 3 -, cada um dos grids criados possibilitou a organização das informações que eram discutidas durante as reuniões de trabalho. Dessa forma, uma dificuldade do cliente, por exemplo, foi alocada na interseção da camada de Dificuldades com a respectiva subetapa em que ele emergia. Este posicionamento de informações foi realizado para todas aquelas que surgiam durante as reuniões, bem como a partir da conversa com os stakeholers identificados durante a concepção da ferramenta. Para facilitar a discussão e localização de elementos no mapa, para cada uma das Subetapas, foi definido um identificador numérico (i.e. 1, 2, 3...). Este ficou localizado acima do nome da Subetapa.

Durante a construção do mapa, cada uma das Macroetapas, Players e Subetapas, após padronizadas e validadas, foram impressas e compuseram a parte superior do mapa. Para os pontos de intercessão entre as Subetapas e os Objetivos/Ganhos/Problemas/Ideias, no entanto, as informações levantadas foram inseridas em post-its. Isso porque para estes campos foram percebidas incertezas quanto às informações mapeadas, e a cada interação com o cliente real, novos entendimentos eram redefinidos. $\mathrm{O}$ intuito aqui era de que a equipe pudesse, a qualquer momento, inserir novas informações ou corrigir aquelas representadas.

Outro elemento utilizado para facilitar o entendimento foram cores. Padronizou-se o uso de post-its com cor verde para a camada de Ganhos, vermelho para a de Problemas, e amarelo para a de Ideias. Na camada de projetos, utilizou-se três cores distintivas: para as Subetapas que 
determinado produto/serviço em desenvolvimento resolvesse parcialmente os elementos mapeados em Ganhos e Problemas, colocava-se um post-it na cor amarela na interseção; para o projeto que resolvesse totalmente Ganhos e Problemas mapeados, a cor verde; e para as Subetapas que planejava-se atuar posteriormente, a cor azul.

\subsection{Dinâmica de interação entre o MCS e Roadmaps}

O MCS funcionou como entrada para a construção de roadmaps no nível de planejamento de produtos/tecnologias (T-Plan). A camada representada por determinado projeto no MCS funcionou como input para a camada de protótipos e/ou tecnologias do roadmap. A lógica utilizada era a de que uma tecnologia individualmente, ou um conjunto de tecnologias compondo um determinado protótipo, resolviam parcialmente ou totalmente a Subetapa relacionada no MCS. O uso configurado dessas duas ferramentas é representado na Figura 4 -.

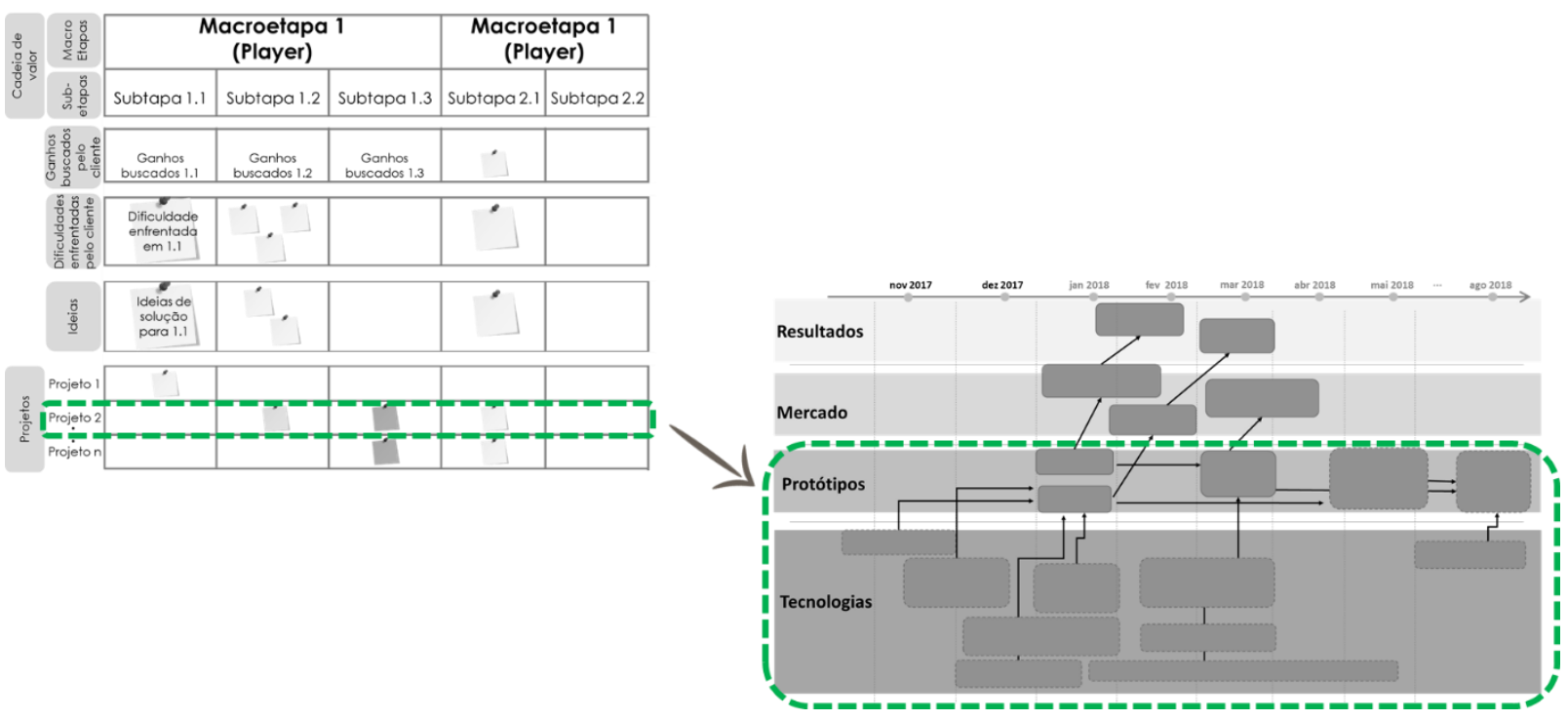

FIGURA 4 - Interação entre o MCS e o Roadmapping

A Figura 5 - apresenta um momento de discussão envolvendo o MCS e o roadmap. 


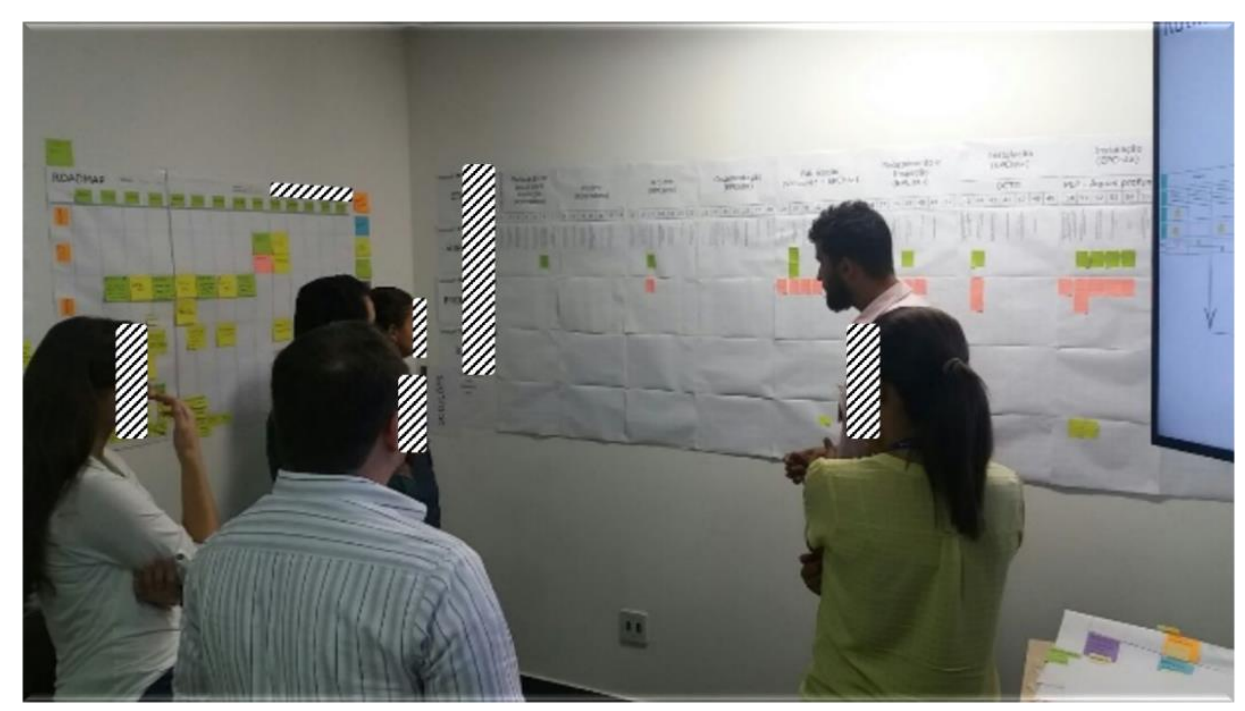

FIGURA 5 - Validação e inserção de dados com equipes de trabalho. À direita, o MCS, à esquerda um Roadmap derivativo criado a partir do mapa

\section{IMPLICAÇÕES E CONSIDERAÇÕES FINAIS}

Embora a iniciativa em análise ainda esteja em desenvolvimento, e por isso ainda possua contornos nebulosos, uma leitura inicial mais ampla do caso esboça, de acordo com a literatura, a formação de uma incubadora corporativa. Isso porque, grosso modo, a equipe tem buscado desenvolver ideias nascidas no ambiente interno, mas que não necessariamente se encaixam diretamente ao corebusiness da mesma; e há o fornecimento de um ambiente interno com financiamento, co-localização, expertise e rede de contatos. Sobre as ideias em desenvolvimento, o que se observou foram os primeiros passos de uma indústria tradicional fabricante de bens em oferecer soluções mais completas por meio de serviços atrelados aos seus produtos, o que, a princípio, esboça uma servitização. Em última instancia, contudo, consideravam transformar eventualmente essas novas soluções em startups (spin-offs).

A partir das ferramentas desenvolvidas, uma nova dinâmica de discussão nas reuniões foi observada. As equipes passaram a interagir diretamente com os mapas criados como suporte à tomada de decisão. Os principais resultados alcançados pelo uso dos métodos configurados, consensuais ao grupo que participou da pesquisa, estão sumarizados no QUADRO 1 -.

QUADRO 1 - Quadro comparativo entre dificuldades observadas e principais resultados alcançados após uso dos métodos configurados. 


\begin{tabular}{|c|c|c|c|}
\hline Nível & Id & Dificuldades observadas & Resultados alcançados \\
\hline \multirow{3}{*}{ Programa } & (a) & $\begin{array}{l}\text { Dificuldade de tomada de decisões em } \\
\text { função do grande volume de } \\
\text { informações oriundas dos diversos } \\
\text { projetos }\end{array}$ & $\begin{array}{l}\text { - Repositório de informações organi } \\
\text { e de fácil acesso para rápida tomadi } \\
\text { decisão; } \\
\text { - Possibilidade de atualização consti } \\
\text { das informações. }\end{array}$ \\
\hline & (b) & $\begin{array}{l}\text { Dificuldade em visualizar um panorama } \\
\text { geral de atuação da incubadora; }\end{array}$ & $\begin{array}{l}\text { - Visão global da atuação de projetc } \\
\text { relação a toda a cadeia de valor; } \\
\text { - Percepção de gaps de atuação. }\end{array}$ \\
\hline & (c) & $\begin{array}{l}\text { Perda de insights de ideias que } \\
\text { emergiam no decorrer das reuniões, mas } \\
\text { que se perdiam por não eram } \\
\text { registradas. }\end{array}$ & - Repositório de ideias. \\
\hline \multirow[t]{3}{*}{ Projeto } & (d) & $\begin{array}{l}\text { Dificuldade de um entendimento } \\
\text { holístico dentre os participantes sobre } \\
\text { para qual cliente, e seu contexto de } \\
\text { trabalho, eram direcionadas as funções } \\
\text { técnicas que desenvolviam; }\end{array}$ & $\begin{array}{l}\text { - Alinhamento da cadeia de atuaçãc } \\
\text { empresa entre membros das equipı } \\
\text { - Alinhamento dos times de } \\
\text { desenvolvimento quanto ao } \\
\text { entendimento holístico da inserção } \\
\text { seus projetos dentro da cadeia de v } \\
\text { - Percepção de gaps de entendimen } \\
\text { (sobre demandas de clientes, seus } \\
\text { Ganhos objetivados e Problemas } \\
\text { vividos). }\end{array}$ \\
\hline & (e) & $\begin{array}{l}\text { Dificuldade de priorização e } \\
\text { sequenciamento no tempo das funções a } \\
\text { serem desenvolvidas; }\end{array}$ & $\begin{array}{l}\text { - Facilitação da priorização de ações } \\
\text { tempo. }\end{array}$ \\
\hline & (f) & $\begin{array}{l}\text { Dificuldade em integrar as informações } \\
\text { de todos os participantes }\end{array}$ & $\begin{array}{l}\text { - Alinhamento de informações entrı } \\
\text { membros de equipes. }\end{array}$ \\
\hline
\end{tabular}

O MCS se mostrou uma importante ferramenta na condução da rotina de trabalho dessa incubadora corporativa. As decisões passaram a ocorrer de forma mais segura e com maior velocidade. Embora não tenha sido utilizado nessa aplicação, uma camada extra é possível que seja acrescida ao mapa: a de produtos ou e/ou serviços em operação. Dessa forma, uma leitura das colunas apresentaria uma visão holística de atuação presente e futura para a empresa.

A ferramenta proposta combina conceitos importantes da servitização, como o entendimento de demandas mais amplas de clientes nos quais a base de produtos da empresa está instalada, bem como conceitos do desenvolvimento de startups, como o entendimento da jornada do cliente, seus ganhos e dores associadas, na condução do desenvolvimento de soluções inovadoras com melhores resultados para a empresa. A solução proposta colabora para o desafio vivenciado por incubadoras corporativas de indústria de bens que buscam aumento da competitividade via desenvolvimento de PSS.

A estratégia de condução da GT permitiu um entendimento fundamentado na prática sobre quais eram os desafios experienciados pela equipe da incubadora corporativa, enquanto a PA, 
de posse desse entendimento, colaborou para o desenvolvimento, em conjunto, de uma solução efetiva para a problemática.

\section{REFERÊNCIAS}

BAINES, T. S. et al. The servitization of manufacturing: A review of literature and reflection on future challenges. Journal of Manufacturing Technology Management, v. 20, n. 5, p. 547-567, 2009.

BRAX, S. A manufacturer becoming service provider - challenges and a paradox. Managing Service Quality: An International Journal, v. 15, n. 2, p. 142-155, abr. 2005.

KARLSSON, U. Service Based manufacturing strategies implication for product development, production and service operations in global companies. POMS College of Service Operations and EurOMA Conference, 2007.

KASTALLI, I. V.; VAN LOOY, B. Servitization: Disentangling the impact of service business model innovation on manufacturing firm performance. Journal of Operations Management, v. 31, n. 4, p. 169-180, maio 2013.

KOHLER, T. Corporate accelerators: Building bridges between corporations and startups. Business Horizons, v. 59, n. 3, p. 347-357, maio 2016.

OLIVA, R.; KALLENBERG, R. Managing the transition from products to services. International Journal of Service Industry Management, v. 14, n. 2, p. 160-172, maio 2003.

OSTERWALDER, A. et al. Value proposition design. New Jersey: John Wiley \& Sons, 2014.

PARK, Y.; GEUM, Y.; LEE, H. Toward integration of products and services: Taxonomy and typology. Journal of Engineering and Technology Management, v. 29, n. 4, p. 528-545, out. 2012.

PHAAL, R.; FARRUKH, C. J. P.; PROBERT, D. R. Technology roadmapping-A planning framework for evolution and revolution. Technological Forecasting and Social Change, v. 71, n. 1-2, p. 5-26, jan. 2004.

PHAAL, R.; FARRUKH, C. J. P.; PROBERT, D. R. Strategic Roadmapping: A Workshopbased Approach for Identifying and Exploring Strategic Issues and Opportunities. Engineering Management Journal, v. 19, n. 1, p. 3-12, mar. 2007.

PHAAL, R.; FARRUKH, C.; PROBERT, D. T-Plan: Fast Start to Technology Roadmapping. Cambridge, UK: University of Cambridge, Institute for Manufacturing, 2001.

PHAAL, R.; FARRUKH, C.; PROBERT, D. Roadmapping for Strategy and Innovation: Aligning technology and markets in a dynamic world. Cambridge, UK: University of Cambridge, Institute for Manufacturing, 2010. 
REN, G.; GREGORY, M. Servitization in manufacturing companies: a conceptualization, critical review and research agenda. Frontiers in Service Conference, 2007.

SONG, W.; SAKAO, T. A customization-oriented framework for design of sustainable product/service system. Journal of Cleaner Production, v. 140, p. 1672-1685, jan. 2017.

TAROZZI, M. O que é a Grounded Theory? Metodologia de pesquisa e de teoria fundamentada nos dados. Petrópolis, RJ: Vozes, 2011.

VANDERMERWE, S.; RADA, J. Servitization of business: Adding value by adding services. European Management Journal, v. 6, n. 4, p. 314-324, dez. 1988.

WEIBLEN, T.; CHESBROUGH, H. W. Engaging with Startups to Enhance Corporate Innovation. California Management Review, v. 57, n. 2, p. 66-90, fev. 2015.

WISE, R.; BAUMGARTNER, P. Go Downstream: The New Profit Imperative in Manufacturing. p. 15, 1999. 